\title{
TELECOLABORAÇÃO TRANSCULTURAĹ E TRANSCONTINENTAL PARA APRENDIZAGEM DE LÍNGUAS ESTRANGEIRAS: PROPOSTAS E DESAFIOS
}

Leila Martins Gonçalves da COSTA ${ }^{1}$

Ana Cristina Biondo SALOMÃO²

Maisa de Alcântara ZAKIR ${ }^{3}$

Propostas de ensino centrado no aluno e não somente na figura do professor ganharam espaço na área de ensino e aprendizagem de línguas a partir da década de 1980, por meio de atividades para promover a interação e negociação de significados. Para Crandall (2000), esse tipo de colaboração desenvolve aspectos afetivos positivos, tais como, redução da ansiedade, aumento de motivação, facilitação do desenvolvimento de atitudes positivas frente à aprendizagem em geral, fomento à autoestima, assim como apoio a distintos estilos de aprendizagem, uma vez que os aprendizes se beneficiam da ajuda dos colegas e o professor não se coloca como o detentor de todo o saber.

Os primeiros relatos de projetos de colaboração on-line entre aprendizes em diferentes localidades somente começaram a aparecer na década de 1990, quando professores de línguas e aprendizes começaram a ter acesso à internet com mais regularidade (O'DOWD, 2007). Entretanto, a ideia de engajar os alunos em tarefas colaborativas em localidades geográficas distintas já era praticada muito antes disso. Os relatos a que se tem acesso datam de 1920, quando o educador francês Célestín Freinet conduziu um projeto com seus alunos de produção de jornais que, posteriormente, foram trocados com alunos de outras partes da França, que também tinham criado publicações (KERN, 2013; O'DOWD, 2007).

1 Costa. University of Miami. E-mail: leilamiami@gmail.com. ORCID ID: https://orcid.org/0000-0001-8039$211 \mathrm{X}$ 
- | Telecolaboração transcultural e transcontinental para aprendizagem de línguas estrangeiras: propostas e desafios

O'Dowd (2018) descreve a telecolaboração (telecollaboration) como o engajamento de um grupo de aprendizes em interações interculturais on-line e projetos em colaboração com parceiros de outros contextos culturais ou localizações geográficas como parte integrante de programas educacionais. O autor explica que diferentes terminologias vêm sendo usadas nos últimos anos para denominar esse tipo de atividade: intercâmbio intercultural on-line (online intercultural exchange), intercâmbio virtual (virtual exchange), COIL (Collaborative Online International Learning), educação intercultural em língua estrangeira mediada pela internet (internet-mediated intercultural foreign language education), ambientes de aprendizagem globalmente em rede (globally networked learning environments), e-tandem e teletandem.

Concordamos com o autor que a profusão de nomenclaturas tem um lado positivo, que mostra que esse tipo de aprendizagem tem sido implementado de diferentes formas e se mostrado adaptável para diferentes contextos e localizações geográficas. Entretanto, isso também demonstra que as práticas e os resultados de pesquisa de iniciativas semelhantes não são conhecidas por membros da comunidade acadêmica de áreas distintas ou afins. O'Dowd (2018) menciona ainda o desafio que as diferentes terminologias e abordagens trazem para a promoção e disseminação de tais atividades entre educadores e legisladores que não estão familiarizados com o conceito.

Atualmente, há uma gama de projetos telecolaborativos, que vão desde propostas individuais, conduzidas por professores em suas salas de aulas, até projetos interinstitucionais, os quais contam com reconhecimento e, muitas vezes, com recursos para sua execução. Há também plataformas internacionais, como eTwinning (MIGUELA, 2007), que buscam colocar em contato os profissionais da educação que trabalham em escolas de diferentes países, para que possam se comunicar, colaborar e desenvolver projetos em conjunto. ${ }^{4}$

Há projetos que buscam a intersecção da aprendizagem de línguas com o componente cultural, como o projeto Cultura, iniciado em 1997, no MIT por Gilberte Furstenberg, Shoggy Waryn e Sabine Levet (GARCÍA; CRAPOTTA, 2007). O objetivo é conectar grupos de alunos por meio de recursos da internet para um intercâmbio cultural, por meio de questionários on-line, posteriormente analisados, assim como de fóruns nos quais os grupos discutem valores culturais e crenças a partir das respostas dadas por eles nos questionários. ${ }^{5}$

\footnotetext{
4 Para mais informações, ver: https://www.etwinning.net/pt/pub/index.htm. 5 Para mais informações, ver: https://cultura.mit.edu/.
} 
Outros exemplos de projetos e portais on-line de telecolaboração atuais são: eTandem Europa ${ }^{6}$, da Ruhr-Universit Bochum, na Alemanha, cujo objetivo é difundir as possibilidades de se aprender uma língua por meio da prática de eTandem, além de oferecer suporte para os interessados em encontrar um parceiro; Lingalog ${ }^{7}$, da Université Lumière Lyon II, na França, que tem como concepção o trabalho colaborativo, colocando em contato falantes nativos de diferentes línguas por meio de uma plataforma que Ihes oferece ferramentas tecnológicas como fórum, chat e wiki.; INTENT ${ }^{8}$ (Integrating Telecollaborative Networks into Foreign Language Higher Education), projeto desenvolvido em várias instituições de ensino superior pelo mundo, que, a partir de uma plataforma, tem como objetivo apoiar professores universitários e mobilizar projetos de telecolaboração entre seus alunos; TILA ${ }^{9}$ (Telecollaboration for Intercultural Language Acquisition), projeto da Comissão Europeia que utiliza a plataforma Moodle e consiste em uma comunidade internacional de professores e pesquisadores interessados em inovar e enriquecer as práticas de ensino de línguas, integrando atividades de telecolaboração com parceiros de diferentes países; Tandem Exchange ${ }^{10}$ e ePals ${ }^{11}$, sites que colocam em contato pessoas interessadas em parcerias colaborativas on-line e presenciais, no caso do primeiro, e apenas on-line, no caso do segundo.

O'Dowd (2014) cita exemplos de projetos que incluem discussões em fóruns internacionais de jornais e revistas, como do LeMonde ou The Guardian, que visam a ir além da interação entre aprendizes e prover oportunidades de comunicação "autêntica", que requerem conhecimento das regras culturais e de registro neste gênero de comunicação. $\mathrm{O}$ autor menciona também iniciativas denominadas "Telecolaboração 2.0", baseadas nos recursos da "web social" que emergiram da criação de ferramentas colaborativas na internet, como os blogs, as wikis e as chamadas redes sociais, como Facebook, Instagram, entre outros, que envolveriam iniciativas mais independentes da sala de aula em comparação aos modelos anteriores.

No caso específico da aprendizagem de línguas, destacamos o eTandem (O'ROURKE, 2007) e o Teletandem (TELLES; VASSALLO, 2006; TELLES, 2009), que colocam pares de falantes de diferentes línguas trabalhando de forma colaborativa por meio de recursos de comunicação síncrona ou assíncrona na Internet para aprenderem a língua um do outro. No caso do eTandem, a conversa é feita por meio de chat, enquanto

6 Para mais informações, ver: http://www.ruhr-uni-bochum.de/tandem-server/etandem/etindex-en.html

7 Para mais informações, ver: http://lingalog.net/dokuwiki/

8 Para mais informações, ver: http://www.uni-collaboration.eu/

9 Para mais informações, ver: http://www.tilaproject.eu/moodle/

10 https://www.tandemexchange.com/

11 www.epals.com 
- | Telecolaboração transcultural e transcontinental para aprendizagem de línguas estrangeiras: propostas e desafios

no Teletandem privilegia-se a compreensão e a produção oral, optando-se por recursos de tecnologia VOIP (Voice over Internet Protocol), como o Skype e, mais recentemente, o Zoom.

Os artigos compilados neste número temático enfocam, em sua maioria, essas duas modalidades de aprendizagem telecolaborativa. Portanto, na próxima seção apresentamos um panorama sobre elas a fim de recuperarmos suas respectivas características, bem como de refletirmos acerca de suas implicações no ensino e aprendizagem de línguas estrangeiras na atualidade.

\section{Do Tandem ao Teletandem ${ }^{12}$}

Tandem é nome dado àquela bicicleta que possui dois bancos e dois conjuntos de pedais, na qual os dois usuários devem trabalhar em conjunto para que consigam atingir o objetivo de fazê-la andar. A imagem da bicicleta cujo funcionamento depende do esforço de seus dois ocupantes é uma metáfora à colaboração entre os parceiros envolvidos no contexto de aprendizagem em tandem. Originalmente, segundo Vassallo e Telles (2006), essa concepção de aprendizagem surgiu na Alemanha nos anos 60 e baseou-se na promoção de parcerias entre aprendizes de línguas estrangeiras, que falavam idiomas diferentes, para que cada parceiro aprendesse a língua do outro. Os autores explicam que foi somente na década de 1970, na Espanha, que o nome Tandem passou a ser usado para denominar essa modalidade de aprendizagem de línguas, sendo que a sistematização de seus princípios ocorreu efetivamente durante os anos de 1990 (BRAMMERTS, 1996).

Vassallo e Telles (2006) afirmam que o currículo do Tandem emerge das necessidades e do envolvimento dos parceiros. Segundo os autores, o contexto de aprendizagem em tandem oferece oportunidade para a socialização e a individualização, uma vez que é baseado em uma autonomia que é entendida como a responsabilidade pela tomada de decisões, não isoladamente, mas "com" e "em relação" ao "outro" (parceiro de tandem). Eles afirmam, ainda, que no Brasil o Tandem foi escassamente praticado em sua modalidade face a face, devido a dificuldades de encontros entre falantes (nativos) de diferentes línguas e de mobilidade por diferentes países, como ocorre na Europa, onde o Tandem surgiu e se tornou bastante popular, especialmente em contextos acadêmicos. Os autores apontam, entretanto, que a expansão da Internet e do uso de e-mails para a comunicação entre as pessoas trouxe popularidade ao regime de tandem para o

12 Optamos por grafar Tandem e Teletandem com letras maiúsculas quando se referirem ao conceito ou projeto e com letras minúsculas quando se referirem à prática ou contexto dessa modalidade de aprendizagem. Nas citações e referências, mantivemos a grafia utilizada pelos respectivos autores. 
ensino de línguas mediado por computador no Brasil e que os avanços tecnológicos da comunicação síncrona abriram novas possibilidades de interação para sessões de tandem a distância.

Nesse sentido, Telles e Vassallo (2006) propuseram o contexto que denominaram Teletandem, no qual a aprendizagem colaborativa em tandem ocorreria por meio de ferramentas digitais na internet, como os aplicativos para comunicação on-line com áudio, vídeo e chat. Os autores, então parceiros de tandem face a face para a aprendizagem de português e italiano, revelam que a ideia dessa nova modalidade on-line surgiu quando Vassallo teve de voltar para a Itália, e, assim, ambos pensaram em novas formas para estabelecer comunicação a distância. A princípio, optaram pelo e-tandem, via e-mail, de caráter assíncrono. Entretanto, sentiam falta da interação oral, visto que este meio somente possibilitava a produção escrita e a leitura. Sua busca os levou às ferramentas de comunicação instantânea na Internet, como o MSN Messenger, o mais comumente usado e disponível na época (anos de 2005 e 2006). Os autores afirmam que, ao testarem essa ferramenta para a aprendizagem em tandem entre si e com amigos, notaram que os resultados foram divertidos, práticos, e, acima de tudo, de baixo custo. Assim, surgiu o projeto Teletandem Brasil: Línguas estrangeiras para todos, com o intuito de investigar as ramificações do modo de aprendizagem que estavam experimentando e seus possíveis resultados para a educação.

O projeto Teletandem Brasil'13 (TELLES; VASSALLO, 2006; TELLES, 2009; BENEDETTI; CONSOLO; VIEIRA-ABRAHÃO, 2010), que foi financiado como projeto temático pela FAPESP (Processo 06/03204-2), apresentou em seu bojo o objetivo de colocar pares de falantes de diferentes línguas trabalhando de forma colaborativa, por meio de recursos de comunicação síncrona na Internet, como o Skype, para aprenderem a língua um do outro. Além disso, ao colocar em perspectiva essa modalidade de ensino e aprendizagem de línguas, o projeto teve como objetivo investigar: (1) o uso da(s) ferramenta(s) de comunicação on-line como instrumento pedagógico para o ensino de línguas em tandem a distância; (2) as características linguísticas, culturais e pedagógicas da interação entre os pares de aprendizes; e (3) o modo como se dá a formação inicial dos alunos-professores (em sua maioria, alunos do curso de Licenciatura em Letras) envolvidos nas interações e o papel do mediador nesse contexto.

13 Este projeto, criado pelo Prof. Dr. João Telles, da FCL/UNESP de Assis, é desenvolvido em conjunto nessa instituição, no IBILCE/UNESP de São José do Rio Preto e na FCL/UNESP de Araraquara. Para mais informações, ver: http://www.teletandembrasil.org e http://teletandem.wixsite.com/fclar. 
- | Telecolaboração transcultural e transcontinental para aprendizagem de línguas estrangeiras: propostas e desafios

Do ponto de vista teórico, os princípios fundamentais que subjazem à parceria dos aprendizes em regime de tandem/teletandem são: o princípio da igualdade (ou separação de línguas ${ }^{14}$ ), da reciprocidade e da autonomia. Há também a previsão de assistência pedagógica à dupla por parte de um mediador para auxiliar o desenvolvimento da aprendizagem, conforme detalharemos mais adiante.

O princípio da igualdade estabelece que as sessões de tandem devem ser compostas de duas partes: cada participante da parceria deve comprometer-se a usar a língua estrangeira, da qual ele é aprendiz, e sua língua materna, mas nunca na mesma parte da sessão, para que ambos tenham oportunidades iguais de praticar a língua estrangeira. Os princípios da autonomia e da reciprocidade, juntos, estabelecem que cada aluno será responsável por seu próprio processo de aprendizagem e pela aprendizagem do outro, e que ambos devem trabalhar em conjunto para delimitarem seus objetivos e escolherem quais serão os melhores métodos para alcançá-los.

Little (2002) afirma que os princípios da reciprocidade e da autonomia no tandem só fazem sentido se existirem conjuntamente, uma vez que o propósito da parceria não será alcançado a não ser que ambos os parceiros se comprometam com sua própria aprendizagem e com a aprendizagem do outro. Segundo Salomão, Silva e Daniel (2009), os princípios estão atrelados, uma vez que a reciprocidade auxilia a separação de línguas, na busca da igualdade de oportunidade de prática para ambos os interagentes ${ }^{15}$. Para as autoras, a reciprocidade também faz parte de uma autonomia colaborativa, coconstruída na interação do par, dado que ambos "trabalham juntos no entendimento da delimitação de suas necessidades, bem como na definição de práticas e/ou procedimentos que os levarão ao alcance mútuo de suas metas" (p. 91). Desse modo, autonomia neste contexto não quer dizer uma tomada de decisões individual, mas sim em conjunto com o outro.

Assim, a relação entre os parceiros é o que constitui a prática de (tele)tandem, sendo, portanto, responsável pelo sucesso ou insucesso das sessões de interação. A interação é o momento em que os parceiros ajudam um ao outro no processo de aprendizagem. É constituída de trocas (tele)colaborativas e recíprocas que ultrapassam os limites de uma conversa trivial, uma vez que os interagentes devem ficar atentos não apenas ao conteúdo mas também à forma dos respectivos turnos. A duração da sessão é definida entre os próprios interagentes, no caso de parcerias não-institucionais. No

14 Segundo Telles e Vassallo (2006), as línguas não devem ser misturadas, e, por isso, os autores denominam esse princípio no teletandem de separação das línguas. Desse modo, cada um dos aprendizes deve beneficiarse igualmente da parceria, por meio da garantia da mesma duração de tempo para a prática das duas línguas. Além disso, existe a recomendação de que cada sessão tenha início com uma língua, assegurando, assim, que ambos os aprendizes tenham acesso ao início da interação na língua-alvo.

15 Interagente é o nome geralmente dado ao participante de teletandem. Neste artigo, usamos as palavras interagente, participante e parceiro de modo intercambiável. 
caso da modalidade de teletandem institucional, em que maioria das sessões é feita em grupos, a duração varia de acordo com o período da aula em que a interação é realizada, geralmente de 50 a 75 minutos.

A literatura sobre a área de(Tele)Tandem prevêalgum tipo de assistência pedagógica por parte de um professor aconselhador (que no Teletandem foi denominado mediador), que será responsável pelo esquema organizacional, prático e teórico no qual o processo se desenvolverá. Autores como Little (2002), Brammerts, Calvert e Kleppin (2002), Stickler (2003) apontam para a necessidade de sessões de aconselhamento para participantes de uma parceria de aprendizagem colaborativa em tandem. A razão para isso, segundo os autores, é que, apesar da motivação do aprendiz em realizar esse tipo de trabalho, ele pode não conseguir explorar totalmente o potencial que o contexto oferece. Portanto, faz-se necessário incentivar os parceiros a usar suas próprias habilidades para aprender de maneira independente e colaborativa e a refletir sobre seus processos de aprendizagem, decidindo seus objetivos e revisando-os continuamente, levando-os também a avaliar seu progresso na aprendizagem.

O aconselhamento, para Brammerts, Calvert e Kleppin (2002), é necessário porque, embora sejam capazes de perceber os fatores que devem utilizar para tomar decisões, como objetivos, hábitos, oportunidades, preferências, muitos aprendizes provavelmente não estão conscientes sobre eles conjuntamente. Segundo os autores, nem sempre é fácil para esses aprendizes traduzir suas decisões em ações e, portanto, sua proposta se volta à reflexão, culminando no auxílio à busca pela autonomia do aprendiz. O aconselhador deve formular perguntas que possam eliciar para o aprendiz elementos relevantes para sua tomada de decisões, tanto a respeito de seus pressupostos e objetivos quanto em relação a mudanças já ocorridas no âmbito da interação, ajudando-o a fazer conexões por meio da introdução de seu conhecimento de especialista e experiência, sem, entretanto, direcionar a prática do aprendiz.

A proposta deStickler(2003) envolvetambém aspectos ligados ao aconselhamento, que levem o aprendiz à autonomia, por meio da exploração e da reflexão. A autora fornece uma lista de sugestões sobre o que o aconselhador deve ou não fazer, geralmente voltadas a comportamentos não direcionadores, e sim exploratórios das atitudes e ações do aprendiz, afirmando, ao final, em uma visão mais pragmática, que tais habilidades só serão compreendidas e aperfeiçoadas pelo aconselhador na prática.

No projeto Teletandem Brasil, as sessões de aconselhamento das parcerias foram denominadas sessões de mediação (TELLES; VASSALLO, 2006), com base na teoria sociocultural. A mediação tem sido realizada de diferentes modos, por alunos 
- | Telecolaboração transcultural e transcontinental para aprendizagem de línguas estrangeiras: propostas e desafios

de graduação e pós-graduação com conhecimento e experiência em teletandem, por meio de sessões individuais ou em grupos, assim como pelo uso de diários reflexivos, dialogados ou não, hospedados em ambientes virtuais de aprendizagem (como Moodle, Teleduc, Google Classroom, Blackboard etc.) e, mais recentemente, até mesmo em redes sociais, como o Facebook.

Segundo Williams e Burden (1999), o termo "mediação", no processo de ensino e aprendizagem, refere-se ao papel de uma pessoa significativa na vida dos alunos, que seleciona e configura as experiências que levarão à aprendizagem. Acreditamos, como já afirmado em Salomão (2011, p. 659), que a ideia de mediação em vez de aconselhamento, trazida pelo projeto Teletandem, entende o auxílio prestado pela figura do mediador "não somente como conselhos sobre como proceder para aprender melhor", mas sim como uma terceira pessoa que se insere na relação de ensino e aprendizagem colaborativos da parceria de interagentes para "auxiliá-los a refletir sobre sua própria prática enquanto aprendizes da língua do outro e professores de sua própria língua".

Salomão (2008) define a figura do mediador como um parceiro mais competente que irá mediar, em termos vygotskyanos, a aprendizagem do interagente, oferecendoIhe a mediação por instrumentos - os recursos tecnológicos, ou não, utilizados -, e a mediação por meio do uso da linguagem, que permeia o processo de interação entre os envolvidos. Telles (2015) corrobora essa ideia ao afirmar que as sessões de mediação são um suporte pedagógico, por meio do diálogo reflexivo, conduzido pelos mediadores enfocando estratégias de aprendizagem e aspectos culturais e linguísticos que emergem durante a sessão de teletandem. Concordamos com o autor que a prática de conduzir uma sessão de mediação requer conhecimento sobre encontros interculturais, discurso e comunicação por parte dos mediadores.

Ao longo dos anos, a mediação tem sido feita por meio de sessões presenciais individuais, como descrito nas pesquisas de Salomão (2008), Mesquita (2008), Bedran (2008), Cavalari (2009), Funo (2015), Elstermann (2017), ou em grupo, como descrito por Carvalho, Messias e Días (2015), ou ainda, de forma semipresencial, com contatos via videoconferência, no Facebook ou em outros aplicativos para discussões em grupo (BEDRAN, 2012). Há ainda experiências de mediação por meio de diários dialogados na plataforma Moodle (EVANGELISTA; SALOMÃO, 2019). Funo, Elstermann e Zakir (2016) sistematizaram as práticas desempenhadas por mediadores em contexto teletandem em uma grade de observação elaborada a partir de questionários abertos respondidos por professores e pesquisadores experientes nessa área. 
Considerando o lugar ocupado por diferentes projetos de telecolaboração no âmbito do ensino e aprendizagem de línguas estrangeiras e visando a colocar em discussão o impacto da aprendizagem em (Tele)Tandem nas práticas e pesquisas da área, foi realizado o I INFLIT (International Meeting on Foreign Language Learning in Tandem: Present, Past and Future), na Universidade de Miami, em Coral Gables, Flórida, EUA, de 27 de fevereiro a 01 de março de 2014. O encontro teve a organização conjunta de pesquisadores do projeto Teletandem Brasil, da Universidade Estadual Paulista (UNESP), e do Departamento de Línguas e Literaturas Modernas da Universidade de Miami, contando com a participação de pesquisadores europeus, norte e sul-americanos.

A conferência de abertura do I INFLIT foi realizada pela Dra. Karin Kleppin, da Universidade de Bochum, Alemanha. A pesquisadora, que foi uma das precursoras do Tandem em seu país, fez um panorama da história do Tandem ao eTandem e apontou a evolução e os caminhos para o futuro desse contexto de aprendizagem de línguas estrangeiras.

A segunda edição do evento foi realizada também na Universidade de Miami de 22 a 24 de março de 2018. O II IMFLIT (cuja grafia foi alterada com a letra M fazendo referência a Meeting na sigla em inglês) teve como tema Transcultural Language Learning: Toward Global Citizenship in (e)Tandem. O encontro também contou com a colaboração dos pesquisadores do projeto Teletandem Brasil, da UNESP, e do Departamento de Línguas e Literaturas Modernas da Universidade de Miami e teve apoio do diretor do Programa de Português, Dr. Steven F. Butterman, e da chefe do departamento, Dra. Lillian Manzor.

O tema da conferência de abertura, ministrada pelo idealizador do projeto Teletandem Brasil, Dr. João Antonio Telles, foi "Performando a transculturalidade na aprendizagem de línguas estrangeiras". O evento também teve a presença de pesquisadores de instituições internacionais da área de telecolaboração, que puderam debater seus trabalhos por meio de um formato de apresentações que priorizou as discussões entre os participantes de cada sessão. Na mesa-redonda "Engendrando diversidade e diferenças culturais em telecolaboração: identidades de gênero e os papéis de mediadores e professores", Dr. Steven Butterman, Dra. Ana Menda, da Universidade de Miami, e Me. Ivian Destro, da Universidade Internacional da Flórida, promoveram um importante debate sobre como tratar a diferença nas interações on-line e na sala de aula, promovendo o respeito e a tolerância nos encontros presenciais e virtuais.

Foi a partir de todas as discussões deflagradas ao longo do II IMFLIT que surgiu a ideia de se pensar uma publicação temática, cujos artigos são apresentados a seguir, sobre as propostas e desafios trazidos pela telecolaboração para a aprendizagem de línguas na atualidade. 
- | Telecolaboração transcultural e transcontinental para aprendizagem de línguas estrangeiras: propostas e desafios

\section{Apresentação do número temático}

Telecolaboração transcultural e transcontinental para aprendizagem de línguas estrangeiras: propostas e desafios, número temático da Revista do Gel, reuniu quinze artigos de pesquisadores de diferentes instituições brasileiras e estrangeiras, que estão organizados em quatro eixos temáticos: (i) contexto de tandem presencial; (ii) experiências de parcerias telecolaborativas institucionais; (iii) (auto)avaliação, aprendizagem de práticas de linguagem e estrutura linguística em teletandem e (iv) questões (inter)culturais, de identidade e (inter)subjetividade.

O primeiro eixo é composto de dois artigos. Em "Face-to-face tandem and eTandem: differences that influence the maintenance of tandem learning activities", Masako Wakisaka compara dois estudos de caso múltiplos em contexto de tandem face a face e e-tandem entre parcerias de japonês-inglês e japonês-alemão. Os resultados trazem implicações para a reflexão sobre os fatores que influenciam a manutenção de atividades nesses contextos colaborativos de aprendizagem.

Em "A deaf and a hearing student learning Portuguese and Libras in a tandem context", Francisco José Quaresma de Figueiredo e Quintino Martins de Oliveira apresentam resultados de um estudo sobre tandem face a face sobre os possíveis benefícios dessa abordagem para falantes de línguas de modalidades diferentes: oral auditivo (português) e visuoespacial (Libras), por meio da análise das estratégias colaborativas adotadas e das negociações estabelecidas nos momentos dos encontros.

O segundo eixo temático deste dossiê, que reúne trabalhos voltados a diferentes vertentes e características de parcerias institucionais, é composto de seis artigos. Karin Adriane Henschel Pobbe Ramos e Kelly Cristiane Henschel Pobbe de Carvalho, em "Estabelecendo objetivos de aprendizagem em contexto de Teletandem", discutem o "estabelecimento de objetivos de aprendizagem para as interações que se dão no contexto virtual do teletandem" a partir da abordagem do Ensino de Línguas para Fins Específicos, ancorando-se metodologicamente na teoria fundamentada em dados. As autoras visam a prover "subsídio a mediadores e interagentes que atuam nesse ambiente on-line de ensino e aprendizagem de línguas, no sentido de que possam direcionar e potencializar o processo a partir dos objetivos estabelecidos".

Edú Alberto Cruz Lecona e María Guadalupe Alfaro Martínez, no artigo intitulado "El Teletándem en el aprendizaje alemán - español: Mediateca Enallt - Unam Y Universidad De Würzburg", apresentam a análise de dados coletados no projeto Aprendizaje Virtual de Lenguas Extranjeras (AVLE), no qual avaliaram o desempenho de alunos que realizaram 
teletandem alemão-espanhol. Os autores discutem os resultados dos desempenhos dos alunos, assim como a função dos centros de aprendizagem de línguas em cada uma das universidades envolvidas.

No artigo "Experiencing teletandem: a collaborative project to encourage students in tandem interactions", Viviane Klen-Alves e Fernanda Franco Tiraboschi discutem os resultados de uma pesquisa-ação realizada em colaboração entre duas professoras, uma de uma escola secundária brasileira e a outra de um colégio técnico americano sobre "o potencial das interações em tandem para o aprimoramento da aprendizagem de segunda língua". Segundo as autoras, os resultados apontam para a atividade telecolaborativa como promotora de atitudes positivas e o aumento da competência intercultural dos alunos.

Em “Desenvolvimento da competência comunicativa oral em PLE: teletandem em foco", Rozana Aparecida Lopes Messias e Michael Jones Ferreira, buscam compreender "em que medida a prática de teletandem institucional integrado influencia o desenvolvimento da competência comunicativa oral" e investigam quais aspectos da fala dos participantes de teletandem evidenciam o desenvolvimento de sua produção oral.

No que tange ao conceito de mediação no contexto de teletandem institucional, Daniela Nogueira de Moraes Garcia e Micheli Gomes de Souza, em seu artigo intitulado "Teletandem mediation on Facebook", abordam o suporte pedagógico ao participante por meio de um grupo fechado em uma rede social. As autoras apresentam "os resultados de uma análise qualitativa interpretativista que revelam que o papel do mediador é focado na promoção de encorajamento e direcionamentos baseados nas teorias e princípios básicos do teletandem".

Michael Abernathy Marsh-Soloway e Olivier Michel Delers, em "New directions in eTandem: an expanded vision of capabilities and practices", apresentam três estudos de caso a partir dos quais propõem inovações ao modelo tradicional de eTandem, com ferramentas e metodologias que motivem e desafiem os alunos a expandir seus horizontes linguísticos, habilidades e conhecimento. Assim, são propostas ideias para que os professores que trabalham com telecolaboração iniciem novos caminhos em eTandem e considerem essas inovações em práticas já consolidadas.

No terceiro eixo temático deste volume, que traz trabalhos sobre (auto)avaliação, aprendizagem de práticas de linguagem e estrutura linguística em teletandem, temos três artigos. Em "A correção de erros e as relações entre avaliação por pares e autoavaliação no ambiente teletandem", Suzi Marques Spatti Cavalari e Ana Carolina Freschi investigam a correção de erros no contexto teletandem, em um estudo de base qualitativa e interpretativista que utiliza como dados gravações de sessões orais. Os participantes são 
- | Telecolaboração transcultural e transcontinental para aprendizagem de línguas estrangeiras: propostas e desafios

três pares de aprendizes que interagem em português e em inglês. Segundo as autoras, a análise revela que "a avaliação por pares envolve não apenas a avaliação do parceiro linguisticamente mais competente, mas, principalmente, a avaliação do próprio aprendiz (autoavaliação) a respeito do que é considerado certo ou errado em sua produção ou compreensão em língua estrangeira".

No artigo intitulado “Episódios relacionados à língua em interações de teletandem: implicações para a formação de professores de PLE", Gabriela Rossatto Franco discute os episódios relacionados à língua emergentes nessas sessões de teletandem, por meio da análise da forma como participantes brasileiros esclarecem dúvidas sobre a língua portuguesa a seus parceiros, destacando a importância de que "os praticantes de teletandem, futuros professores de língua estrangeira, desenvolvam uma atitude reflexiva sobre as práticas de linguagem".

Edvan P. Brito, em "The variation of obligatory preposition-article contractions in the interlanguage of adult learners of Portuguese", analisa "a variação sociolinguística de contrações obrigatórias entre a preposição de e os artigos definidos na interlíngua de aprendizes adultos de português como língua estrangeira nos Estados Unidos", demonstrando que "dados de fala de interações telecolaborativas podem ser usados como uma das técnicas para coleta de dados em estudos de variação de interlíngua de grande porte".

O quarto eixo, que reúne trabalhos voltados a questões (inter)culturais, de identidade e subjetividade, reúne quatro artigos. Aurora Castillo-Scott, em "Teaching social issues through cinema and teletandem", apresenta uma experiência pedagógica de uso de cinema e teletandem para promover habilidades linguísticas, abordando questões socioculturais, por meio de conversas focadas em problemas culturais, raciais, de gênero e sociopolíticos associados à cultura hispânica.

Kaitlin Teske e Alexis Vollmer Rivera, em "A critical exploration of heritage language learners' identities within HelloTalk", investigam como aprendizes de língua de herança constroem suas identidades no contexto de aprendizagem de eTandem, por meio do aplicativo HelloTalk. A partir de reflexões relatadas pelos participantes do estudo e com base na Análise de Conteúdo no âmbito da Linguística Aplicada Crítica, os resultados apontam que, embora algumas características promovam relações colaborativas de poder, em geral, a configuração do aplicativo promove relações coercitivas de poder.

Em "Deconstructing language learners' feelings of inferiority through teletandem", Paula A. Zulaica-Gómez investiga de que modo, no caso de alunos mexicanos que estudam inglês como língua estrangeira, "vários fatores socioculturais, resultantes da 
história colonial do país, afetam sua motivação e atitude em relação ao inglês". A autora analisa de que maneira as percepções e atitudes em relação ao inglês afetam a disposição dos aprendizes mexicanos de participar de sessões de teletandem e de que modo o teletandem pode romper com noções preconcebidas.

Gerson Rossi dos Santos e Douglas Altamiro Consolo, no artigo intitulado "Understanding teletandem language learning from an intersubjective perspective", abordam o estabelecimento da intersubjetividade nas sessões orais de teletandem em uma perspectiva hermenêutica. Os resultados mostram que o estabelecimento da intersubjetividade abrange tanto uma dimensão de parceiro para parceiro imediato quanto uma dimensão mais ampla baseada na comunidade.

Esperamos que os artigos deste número temático possam contribuir para a discussão sobre como o desenvolvimento dos recursos digitais ligados à internet tem mudado as práticas comunicativas do mundo atual. Lembramos que Kern, Ware e Warschauer (2004) já sugeriram que esse momento do ensino de línguas mediado por computador seria uma "segunda onda", constituída principalmente pela telecolaboração a distância orientada pelas relações interculturais. Isso é corroborado pelos muitos projetos que têm sido implementados ao redor do mundo, diminuindo espaços geográficos e trazendo à tona uma expansão do contexto de instrução da sala de aula, como atividade local, para interação entre comunidades e nações (THORNE, 2006).

Por fim, concordamos com O'Dowd (2014) que a complexidade e as dificuldades enfrentadas ao se organizar e executar um projeto telecolaborativo podem desencorajar os professores de implementar tal iniciativa em suas aulas. Entretanto, é importante lembrar também que a telecolaboração é um claro exemplo de como é possível articular o ensino de língua estrangeira em sala de aula com experiências de contato com outros aprendizes, que podem ser extremamente enriquecedoras, tanto no nível linguístico quanto (inter) cultural. Afinal, o impacto das relações que se estabelecem (tele)colaborativamente proporciona à aprendizagem de línguas novas oportunidades de explorar as possibilidades de atuação entre os envolvidos no mundo globalizado, constituindo-se, assim, de modo cada vez mais efetivo o campo da telecolaboração transcultural e transcontinental. 
- Telecolaboração transcultural e transcontinental para aprendizagem de línguas estrangeiras: propostas e desafios

\section{Referências}

BEDRAN, P. F. A (re)construção das crenças do par interagente e dos professoresmediadores no teletandem. 2008. Dissertação (Mestrado em Estudos Linguísticos) Instituto de Biociências, Letras e Ciências Exatas, Universidade Estadual Paulista, São José do Rio Preto, 2008.

BEDRAN, P. F. A Formação Inicial do Professor de Línguas no e para o Contexto Virtual e a Construção de Comunidades de Prática. 2012. Tese (Doutorado em Estudos Linguísticos) - Instituto de Biociências, Letras e Ciências Exatas, Universidade Estadual Paulista, São José do Rio Preto, 2012.

BenEDETTI, A. M.; CONSOlO, D. A.; VIEIRA-ABRAHÃO, M. H. Pesquisas em ensino e aprendizagem no Teletandem Brasil: línguas estrangeiras para todos. Campinas: Pontes, 2010.

BRAMMERTS, $\mathrm{H}$. Tandem language learning via the internet and the International E-Mail Tandem Network. In: LITTLE, D.; BRAMMERTS, H. (eds.). A Guide to Language Learning in Tandem via the Internet. CLCS Occasional Paper, 46, p. 9-22, 1996.

BRAMMERTS, H.; CALVERT, M.; KLEPPIN, K. Objectivos e formas de aconselhamento individual. In: DELILLE, K. H.; CHICHORRO, A. F. Aprendizagem autónoma de línguas em tandem. Lisboa: Colibri, 2002. p. 69-79.

CAVALARI, S. M. S. A auto-avaliação em um contexto de ensino-aprendizagem de línguas em tandem via chat. 2009. Tese (Doutorado em Estudos Linguísticos) - Instituto de Biociências, Letras e Ciências Exatas, Universidade Estadual Paulista, São José do Rio Preto, 2009.

CARVALHO, K. C. H. P. de; MESSIAS, R. A. L.; DÍAS, A. M. Teletandem within the Context of closely-related languages: A Portuguese-Spanish interinstitutional experience. DELTA - Revista de Documentação e Estudos em Linguística Teórica e Aplicada, v. 31, n. 3, p. 711-728, 2015.

CRANDALL, J. J. El aprendizaje cooperativo de idiomas y los factores afectivos. In: ARNOLD, J. (ed.). La dimensión afectiva en el aprendizaje de idiomas. Tradução de Alejandro Valero. Madrid: Cambridge University Press, 2000. p. 243-260. 
Leila Martins Gonçalves da COSTA | Ana Cristina Biondo SALOMÃO | Maisa de Alcântara ZAKIR | •

ELSTERMANN, A. K. Learner Support in Telecollaboration: Peer Group Mediation in Teletandem. Bochum: Ruhr-Universität, 2017.

EVANGELISTA, M. C. R. G.; SALOMÃO, A. C. B. Mediation in Teletandem: from face to face dialogue to dialogical reflective journals. Pandaemonium Germanicum, v. 22, n. 36, p. 153-177, 2019.

FUNO, L. B. A. Teletandem: um estudo sobre identidades culturais e sessões de mediação da aprendizagem. 2015. Tese (Doutorado em Estudos Linguísticos) - Instituto de Biociências, Letras e Ciências Exatas, Universidade Estadual Paulista, São José do Rio Preto, 2015.

FUNO, L. B. A.; ELSTERMANN, A. K.; ZAKIR, M. A. Observação pedagógica em contexto de aprendizagem telecolaborativa. Calidoscópio, v. 14, n. 3, p. 433-447, 2016.

GARCÍA, J. S.; CRAPOTTA, J. Models of Telecollaboration (2): Cultura. In: O'DOWD, R. (ed.). Online Intercultural Exchange: An Introduction for Foreign Language Teachers. Clevedon: Multilingual Matters, 2007. p. 62-84.

KERN, R. Technology in language learning. In: SIMPSON, J. (ed.). The Routledge Handbook of Applied Linguistics. London \& New York: Routledge, 2013. p. 200-2014.

KERN, R.; WARE, P.; WARSCHAUER, M. Crossing frontiers: new directions in online pedagogy and research. Annual review of Applied Linguistics, 24, p. 243-260, 2004.

LITTLE, D. A aprendizagem de línguas em tandem e a autonomia do aprendente. In: DELILLE, K. H.; CHICHORRO, A. F. Aprendizagem autónoma de línguas em tandem. Lisboa: Colibri, 2002. p. 27-35.

MESQUITA, A. F. Crenças e práticas de avaliação no processo interativo e na mediação de um par no tandem a distância: Um estudo de caso. 2008. Dissertação (Mestrado em Estudos Linguísticos) - Instituto de Biociências, Letras e Ciências Exatas, Universidade Estadual Paulista, São José do Rio Preto, 2008.

MIGUELA, A. D. Models of telecollaboration (3): eTwinning. In: O'DOWD, R. (ed.). Online Intercultural Exchange: An Introduction for Foreign Language Teachers. Clevedon: Multilingual Matters, 2007. p. 85-104. 
- Telecolaboração transcultural e transcontinental para aprendizagem de línguas estrangeiras: propostas e desafios

O'DOWD, R. (ed.). Online Intercultural Exchange: An Introduction for Foreign Language Teachers. Clevedon: Multilingual Matters, 2007.

O'DOWD, R. Intercultural communicative competence through telecollaboration. In: JACKSON, J. The Routledge Handbook of Language and Intercultural Communication. New York: Routledge, 2014. p. 340-356.

O'DOWD, R. From telecollaboration to virtual exchange: state-of-the-art and the role of UNICollaboration in moving forward. Journal of Virtual Exchange, n. 1, p. 1-23, 2018.

O'ROURKE, B. Models of Telecollaboration (1): eTandem. In: O'DOWD, R. (ed.). Online Intercultural Exchange: An Introduction for Foreign Language Teachers. Clevedon: Multilingual Matters, 2007. p. 41-61.

SALOMÃO, A. C. B. Gerenciamento e estratégias pedagógicas na mediação dos pares no teletandem e seus reflexos para as práticas pedagógicas dos interagentes. 2008. Dissertação (Mestrado em Estudos Linguísticos) - Instituto de Biociências, Letras e Ciências Exatas, Universidade Estadual Paulista, São José do Rio Preto, 2008.

SALOMÃO, A. C. B. A formação do formador de professores: perspectivas de colaboração entre graduandos e pós-graduandos no projeto Teletandem Brasil. Revista Brasileira de Linguística Aplicada [on-line], v. 11, n. 3, p. 653-677, 2011. Disponível em: http://dx.doi. org/10.1590/S1984-63982011000300004. Acesso em: 15 nov. 2018.

SALOMÃO, A. C. B.; SILVA, A. C.; DANIEL, F. de G. A aprendizagem colaborativa em Tandem: um olhar sobre seus princípios. In: TELLES, J. A. Teletandem: um contexto virtual, autônomo e colaborativo para aprendizagem de línguas estrangeiras no século XXI. Campinas: Pontes, 2009. p. 75-92.

STICKLER, U. Student-centred counselling for tandem advising. In: LEWIS, T.; WALKER, L. (eds.). Autonomous language learning in tandem. Sheffield, UK: Academy Electronic Publications, 2003. p. 115-122.

TELLES, J. A.; VASSALLO, M. L. Foreign language learning in-tandem: Teletandem as an alternative proposal in CALLT. The ESPecialist, v. 27, n. 2, p. 189-212, 2006.

TELLES, J. A. Teletandem: um contexto virtual, autônomo e colaborativo para aprendizagem de línguas estrangeiras no século XXI. Campinas: Pontes, 2009. 
Leila Martins Gonçalves da COSTA | Ana Cristina Biondo SALOMÃO | Maisa de Alcântara ZAKIR | •

TELLES, J. A. Learning foreign languages in teletandem: Resources and strategies. DELTA Revista de Estudos em Linguística Teórica e Aplicada, v. 31, n. 3, 651-680, 2015.

THORNE, S. L. Pedagogical and Praxiological Lessons from Internet-mediated Intercultural Foreign Language Education Research. In: BELZ, J. A.; THORNE, S. L. (eds.). AAUSC 2005: Internet-mediated Intercultural Foreign Language Education. Boston: Thomson Heinle, 2006.

VASSALLO, M. L.; TELLES, J. A. Foreign language learning in-tandem: Theoretical principles and research perspectives. The ESPecialist, v. 27, n. 1, p. 83-118, 2006.

WILLIAMS, M.; BURDEN, R. Psicología para profesores de idiomas. Enfoque del constructivismo social. Madrid: Cambridge University Press, 1999.

COMO CITAR ESTE ARTIGO: COSTA, Leila Martins Gonçalves da; SALOMÃO, Ana Cristina Biondo; ZAKIR, Maisa de Alcântara. Telecolaboração transcultural e transcontinental para aprendizagem de línguas estrangeiras: propostas e desafios. Revista do GEL, v. 15, n. 3, p. 9-25, 2018. Disponível em: https://revistadogel.gel.org.br/

DOI: http://dx.doi.org/10.21165/gel.v15i3.2433 